\title{
Every reason to discontinue lithium
}

\author{
Manuel E Fuentes Salgado ${ }^{1,3}$, Bruce Sutor ${ }^{1}$, Robert C Albright $\mathrm{Jr}^{2}$ and Mark A Frye ${ }^{1 *}$
}

\begin{abstract}
Lithium as a gold standard therapy for bipolar disorder is well known to have a number of medical comorbidities that impact renal, parathyroid, and thyroid function. Despite these medical comorbidities, there remains a group of lithium-responsive lithium-treated patients who have maintained mood stability for decades. The risk/benefit ratio of end organ toxicity/mood stability must be evaluated in each individual case.
\end{abstract}

Keywords: Lithium; Toxicity; Efficacy

\section{Correspondence}

Lithium is the gold standard therapy for bipolar disorder, treating acute mania and depression, preventing episode recurrence, and reducing suicide risk (Cipriani et al. 2005; Geddes et al. 2004). Because of its side effect burden, narrow therapeutic window, and an increasing pharmacopeia, there are clinical situations in which lithium is no longer a first line treatment and/or when toxicity necessitates drug discontinuation (Malhi et al. 2012; McKnight et al. 2012).

Lithium has an acute (nephrogenic diabetes insipidus) and chronic (interstitial fibrosis, segmental glomerulosclerosis, and/or tubulointerstitial changes associated with renal insufficiency) effect on the kidney (Baig et al. 2011; Bassilios et al. 2008; Grunfeld and Rossier 2009). Lithium interferes with thyroid metabolism and increases the incidence of overt and subclinical hypothyroidism and may cause hyperparathyroidism with a high incidence of multiglandular disease (Hundley et al. 2005; Kleiner et al. 1999). Renal, thyroid, and parathyroid toxicity related to longterm treatment often contribute to drug discontinuation (Hundley et al. 2005; Kleiner et al. 1999; McKnight et al. 2012). We report a case of lithium-responsive bipolar disorder and the risk/benefit ratio of ongoing mood stability vs. end organ toxicity.

Ms. D is a 60-year-old woman with bipolar I disorder. Her early course of illness was characterized by two hospitalizations in 1982 for major depression. Her only hospitalization for euphoric mania was in 1983, at which time lithium was started. After mood stability

\footnotetext{
* Correspondence: mfrye@mayo.edu

'Department of Psychiatry and Psychology, Mayo Clinic Depression Center, Rochester, MN 55901, USA

Full list of author information is available at the end of the article
}

was achieved, the medication was discontinued, with recurrence of major depression several months later. Restarting lithium, she noted mood improvement, maintained lithium 1,200 mg for another 3 years (1985 to 1988) before discontinuing the drug. For a 1996 postpartum depression unresponsive to divalproex sodium, she returned to lithium and again achieved mood stability (1997 to 2001). There was no family history of bipolar disorder or previous use of lithium.

In August 2001, she was diagnosed with a retroperitoneal myxofibrosarcoma with kidney involvement and underwent a right nephrectomy. Adjustment to her lithium dose was done to maintain levels at 0.6 to $0.8 \mathrm{mmol} / \mathrm{L}$. Her serum creatinine nonetheless slowly began to increase, with a $1.5 \mathrm{mg} / \mathrm{dL}$ peak 10 years later in 2011. The diagnostic work-up included a creatinine clearance $(42 \mathrm{~mL} / \mathrm{min})$ and a computerized tomography scan that identified small cysts. Stage 3 chronic renal insufficiency and chronic interstitial nephritis of her left solitary kidney was diagnosed and after nearly 15 years of non-continuous lithium treatment (three trial periods) the drug was discontinued.

Within 1 week of starting carbamazepine, she developed a severe vaginal and perineal rash. The drug was discontinued, and treatment was switched to maintenance risperidone $1 \mathrm{mg}$. After 5 months of treatment, symptoms of major depression emerged. She was titrated to a quetiapine dose of $100 \mathrm{mg}$ but complained of excessive sedation and worsening depression. In 2011, lithium was reintroduced and remains today, dosed at 300 to $450 \mathrm{mg}$ maintaining levels between 0.4 and $0.6 \mathrm{mmol} / \mathrm{L}$. There was consideration of a lamotrigine trial, but she declined due to the previous adverse reaction of other 
anticonvulsants and her insistence upon returning to lithium, which she found helpful.

Over time, her creatinine/estimated glomerular filtration rate has progressed from 1.5/36 in 2009 to $1.8 / 29$ in 2014 . Since 2011, her thyroid-stimulating hormone has fluctuated between subclinical hypothyroidism (thyroid-stimulating hormone $6.8 \mathrm{mIU} / \mathrm{L}$ ) and transient subclinical hyperthyroidism (0.01) status postparathyroidectomy; she has never been on long-term levothyroxine replacement. In 2012, she was hospitalized for a sudden abdominal pain secondary to a cecal volvulus that was resolved by ileocecectomy. During the hospitalization, she developed asymptomatic hypernatremia probably secondary to nephrogenic diabetes insipidus related to lithium therapy. In 2013, mild hypercalcemia was identified with further testing revealing primary hyperparathyroidism; calcium supplement was discontinued and a partial parathyroidectomy was performed. Subsequent calcium levels have remained slightly elevated, without evidence for metabolic or surgically active urolithiasis.

\section{Discussion}

There remains a group of lithium-treated patients who have maintained decades of mood stability and who, when the drug is discontinued for side effect toxicity, develop significant mood destabilization. The risk/benefit of end organ toxicity/mood stability must be evaluated in each individual case. Up to $40 \%$ of the patients who received long-term lithium experienced nephrogenic diabetes insipidus; whereas the risk of end-stage renal failure is greater than in healthy controls, the absolute risk is low approximately 0.5\% (Baig et al. 2011; McKnight et al. 2012). The benefit of discontinuing lithium once the kidney begins to fail is a controversial decision. There are no clear guidelines about when and how to stop the prescription. While not in this case, the beneficial renal effect of discontinuing lithium is observed mainly in patients with moderate chronic kidney disease (creatinine clearance $>40 \mathrm{~mL} / \mathrm{min}$ ) (Baig et al. 2011; McKnight et al. 2012). Moreover, recent research from a Swedish renal registry suggests that more modern treatment principles of lithium maintenance (i.e., serum levels 0.5 to $0.8 \mathrm{mmol} / \mathrm{L}$ vs. 0.8 to $1.2 \mathrm{mmol} / \mathrm{L}$, regular and frequent renal function monitoring) may have reduced this lithium-associated renal event (Aiff et al. 2014). The rate of hypothyroidism and primary hyperparathyroidism is increased sixfold and tenfold, respectively, related to lithium treatment (McKnight et al. 2012). There are no clear recommendations about the threshold for initiation of thyroid supplementation in lithium-treated patients with subclinical hypothyroidism. However, it is increasingly recognized that subtle change in thyroid-stimulating hormone and free thyroxine are associated with rapid cycling and bipolar depression recurrence (Frye et al. 1999; Frye et al. 2009). Lithium can be associated with hypercalcemia more commonly than hyperparathyroidism (Lally et al. 2013) and can exacerbate preexisting hyperparathyroidism, increasing the rate of multiglandular disease; subtotal parathyroidectomy, intraoperative parathyroid hormone determination-guided excision, or the use of calcimimetics are the proposed treatment options (Szalat et al. 2009). In this case, after subtotal parathyroidectomy, the serum calcium levels remained elevated (parathyroid hormone normal), which is not the usual response in the lithium-related cases. In the final overview of lithium-related toxicity, it is important to differentiate between side effects due to inappropriate use of the drug (from the standpoint of both overdose or dehydration) and practice evolution of lithium maintenance treatment monitoring (Aiff et al. 2014). Clinical assessment for appropriateness of lithium treatment selection (i.e., response predictors) and close clinical monitoring may decrease the risk/benefit ratio.

\section{Conclusion}

The patient's decision to always return to lithium was based on the recognition of superior mood stabilization over other treatments, support and validation from her family regarding treatment benefit of lithium, and access to close medical follow-up. Her lithium course of illness response was remarkable for several reasons. First, she had clear response predictors (i.e., euphoric mood, absence of substance abuse, non-rapid cycling) with evidence of drug discontinuation three times with depressive episode recurrence, and, more notably, re-responsive illness with lithium reintroduction. Second, the patient had either poor tolerability (quetiapine), adverse allergic reaction (carbamazepine), or non-response (risperidone, divalproex sodium) to other treatment options. Her multidisciplinary treatment including psychiatry and nephrology teams tried to use other mood stabilizers that could help her to stabilize her mood and not deteriorate her physical health, but every other treatment failed for lack of efficacy or poor tolerability. In spite of her medical illness burden (status postnephrectomy, stage 3 renal failure, nephrogenic diabetes insipidus, status posthyperparathyroid resection with persistent hypercalcemia, history of subclinical hypothyroidism, and hyperthyroidism), lithium continued to be her maintenance mood stabilizer. The patient had every reason to discontinue lithium, but in her opinion, guided by her medical providers, lithium provided the best mood stabilization for management of bipolar disorder.

\section{Abbreviations \\ Mg: milligram(s); mg/dL: milligram(s) per deciliter; mIU/L: milli-international units per liter; $\mathrm{mL} / \mathrm{min}$ : milliliter(s) per minute; mmol/L: millimole(s) per liter.}

\section{Competing interests}

Dr. Frye declares as potential competing interests grant support (AssureRx, Janssen Research \& Development, Mayo Foundation, Myriad, National Institute of Alcohol Abuse and Alcoholism, National Institute of Mental Health, Pfizer), consultant (Janssen Research \& Development, LLC, Mitsubishi 
Tanabe Pharma Corporation, Myriad, Sunovion, Supernus Pharmaceuticals, Teva Pharmaceuticals), and CME/Travel Support (CME Outfitters Inc.). The remaining authors declare that they have no competing interests.

\section{Authors' contributions}

MEFS made substantial contributions to conception and design, acquisition of data, and analysis and interpretation of data, was involved in drafting the manuscript and revising it critically for important intellectual content, and gave final approval of the version to be published. BS and RCA were involved in drafting the manuscript and revising it critically for important intellectual content and gave final approval of the version to be published. MAF made substantial contributions to conception and design, acquisition of data, and analysis and interpretation of data, was involved in drafting the manuscript and revising it critically for important intellectual content, gave final approval of the version to be published, and agreed to be accountable for all aspects of the work in ensuring that questions related to the accuracy or integrity of any part of the work are appropriately investigated and resolved. All authors read and approved the final manuscript.

\section{Acknowledgements}

The authors recognize and express gratitude for the patients they work with every day who are a continued source of inspiration and hope.

\section{Author details}

'Department of Psychiatry and Psychology, Mayo Clinic Depression Center, Rochester, MN 55901, USA. ${ }^{2}$ Department of Internal Medicine, Division of Nephrology, Mayo Clinic, Rochester, MN 55901, USA. ${ }^{3}$ Department of Psychiatry, Facultad de Medicina Clínica Allemana, Universidad del Desarrollo, Vitacura 5951, Comuna de Vitacura, Santiago, Chile.

\section{Received: 11 July 2014 Accepted: 23 August 2014}

Published online: 08 November 2014

\section{References}

Aiff H, Attman PO, Aurell M, Bendz H, Schon S, Svedlund J (2014) The impact of modern treatment principles may have eliminated lithium-induced renal failure. J Psychopharmacol 28:151-154, doi:10.1177/0269881113516202

Baig A, Adewale AS, Borra S (2011) Quiz page August 2011: lithium-induced nephrotic syndrome. Am J Kidney Dis 58:A25-A28, do:10.1053/j. ajkd.2011.04.016

Bassilios N, Martel P, Godard V, Froissart M, Grunfeld JP, Stengel B (2008) Monitoring of glomerular filtration rate in lithium-treated outpatients-an ambulatory laboratory database surveillance. Nephrol Dial Transplant 23:562-565, doi:gfm567

Cipriani A, Pretty H, Hawton K, Geddes JR (2005) Lithium in the prevention of suicidal behavior and all-cause mortality in patients with mood disorders: a systematic review of randomized trials. Am J Psychiatry 162:1805-1819, doi:162/10/1805

Frye MA, Denicoff KD, Bryan AL, Smith-Jackson EE, Ali SO, Luckenbaugh D, Leverich GS, Post RM (1999) Association between lower serum free T4 and greater mood instability and depression in lithium-maintained bipolar patients. Am J Psychiatry 156:1909-1914

Frye MA, Yatham L, Ketter TA, Goldberg J, Suppes T, Calabrese JR, Bowden CL, Bourne E, Bahn RS, Adams B (2009) Depressive relapse during lithium treatment associated with increased serum thyroid-stimulating hormone: results from two placebo-controlled bipolar I maintenance studies. Acta Psychiatr Scand 120:10-13, doi:10.1111/j.1600-0447.2008.01343.x

Geddes JR, Burgess S, Hawton K, Jamison K, Goodwin GM (2004) Long-term lithium therapy for bipolar disorder: systematic review and meta-analysis of randomized controlled trials. Am J Psychiatry 161:217-222

Grunfeld JP, Rossier BC (2009) Lithium nephrotoxicity revisited. Nat Rev Nephrol 5:270-276, doi:10.1038/nrneph.2009.43

Hundley JC, Woodrum DT, Saunders BD, Doherty GM, Gauger PG (2005) Revisiting lithium-associated hyperparathyroidism in the era of intraoperative parathyroid hormone monitoring. Surgery 138:1027-1031, discussion 31-2. doi:S0039-6060(05)00567-2
Kleiner J, Altshuler L, Hendrick V, Hershman JM (1999) Lithium-induced subclinical hypothyroidism: review of the literature and guidelines for treatment. J Clin Psychiatry 60:249-255

Lally J, Lee B, McDonald C (2013) Prevalence of hypercalcemia in patients on maintenance lithium therapy monitored in primary care. Ir Med J 106:15-17

Malhi GS, Tanious M, Das P, Berk M (2012) The science and practice of lithium therapy. Aust N Z J Psychiatry 46:192-211, doi:10.1177/0004867412437346

McKnight RF, Adida M, Budge K, Stockton S, Goodwin GM, Geddes JR (2012) Lithium toxicity profile: a systematic review and meta-analysis. Lancet 379:721-728, doi:10.1016/S0140-6736(11)61516-X

Szalat A, Mazeh H, Freund HR (2009) Lithium-associated hyperparathyroidism: report of four cases and review of the literature. Eur J Endocrinol 160:317-323, doi:10.1530/EJE-08-0620

\section{doi:10.1186/s40345-014-0012-y}

Cite this article as: Salgado et al:: Every reason to discontinue lithium.

International Journal of Bipolar Disorders 2014 2:12.

\section{Submit your manuscript to a SpringerOpen ${ }^{\circ}$ journal and benefit from:}

- Convenient online submission

Rigorous peer review

- Immediate publication on acceptance

- Open access: articles freely available online

- High visibility within the field

- Retaining the copyright to your article

Submit your next manuscript at $\gg$ springeropen.com 